\title{
Efficacy and safety of novel oral anticoagulants for treatment of acute venous thromboembolism: direct and adjusted indirect meta-analysis of randomised controlled trials
}

\author{
(c) $\underset{1}{(1)(8)}$ OPEN ACCESS
}

\author{
Benjamin D Fox visiting professor ${ }^{1}$, Susan R Kahn professor of medicine ${ }^{2}$, David Langleben professor \\ of medicine ${ }^{1}$, Mark J Eisenberg professor of medicine ${ }^{12}$, Avi Shimony visiting scientist ${ }^{12}$
}

${ }^{1}$ Center for Pulmonary Vascular Disease and Division of Cardiology, Lady Davis Institute, Jewish General Hospital, McGill University, Montreal, QC, Canada H3T 1E2; ${ }^{2}$ Division of Internal Medicine and Department of Medicine, McGill University, Center for Clinical Epidemiology and Community Studies, Lady Davis Institute, Jewish General Hospital, Montreal, QC

\begin{abstract}
Objective To critically review the effectiveness of the novel oral anticoagulants (rivaroxaban, dabigatran, ximelagatran, and apixaban) in the treatment of acute venous thromboembolism.

Design Systematic review and random effects meta-analysis. Data were extracted independently by two investigators. An adjusted indirect comparison was performed to compare between novel oral anticoagulants.

Data sources Medline, Embase, and Cochrane Library (from inception to April 2012). Hand searching of relevant scientific works and contact with experts.

Study selection Randomised controlled trials of novel oral anticoagulants compared with vitamin $\mathrm{K}$ antagonists for acute venous thromboembolism. Selected outcomes were recurrent events, major bleeding, and all cause mortality.

Results Nine studies met our inclusion criteria, involving 16701 patients evaluated for efficacy and 16611 for safety. Data were stratified according to different novel oral anticoagulants. For recurrent acute venous thromboembolism, there were no significant differences in events rates between any of the anticoagulants and conventional treatment (rivaroxaban (four studies): relative risk $0.85,95 \%$ confidence interval 0.55 to 1.31 ; dabigatran (two studies): $1.09,0.76$ to 1.57 ; ximelagatran (two studies): 1.06, 0.62 to 1.80; and apixaban (one study): 0.98, 0.20 to 4.79). Rivaroxaban reduced the risk of major bleeding compared with conventional treatment $(0.57,0.39$ to 0.84$)$, whereas other novel oral anticoagulants did not $(0.76$ (0.49 to 1.18$)$ for dabigatran; 0.54 (0.28 to 1.03) for ximelagatran; 2.95 ( 0.12 to 71.82 ) for apixaban). For all cause mortality there were no significant differences between the novel oral
\end{abstract}

anticoagulants and conventional treatment $(0.96(0.72$ to 1.27$)$ for rivaroxaban; 1.00 (0.67 to 1.50$)$ for dabigatran; 0.67 (0.42 to 1.08) for ximelagatran; 6.89 (0.36 to 132.06 ) for apixaban). The adjusted indirect comparison between rivaroxaban and dabigatran did not show superiority of either drug over the others for major bleeding $(0.75,0.41$ to 1.34$)$ or the other endpoints.

Conclusions Compared with vitamin $\mathrm{K}$ antagonists, the novel oral anticoagulants had a similar risk of recurrence of acute venous thromboembolism and all cause mortality, though rivaroxaban was associated with a reduced risk of bleeding.

\section{Introduction}

Venous thromboembolism is a common condition that is associated with considerable morbidity and mortality. ${ }^{1}$ The mainstay of treatment has been initial use of parenteral anticoagulants followed by longer term use of oral vitamin $\mathrm{K}$ antagonists. ${ }^{1}$ While the vitamin $\mathrm{K}$ antagonists are effective at preventing propagation and recurrence, they are also associated with an increased risk of bleeding and the need for laboratory monitoring. ${ }^{2}$ In addition, they have potential for multiple drug-drug interactions, which are often clinically important because of their narrow therapeutic index. In the past decade two classes of novel oral anticoagulants have been developed: direct thrombin inhibitors and factor $\mathrm{Xa}$ inhibitors. Factor $\mathrm{Xa}$ inhibitors prevent cleavage of prothrombin to thrombin, whereas the direct thrombin inhibitors prevent thrombin from cleaving fibrinogen. ${ }^{3}$ These agents have been extensively studied for prophylaxis of acute venous thromboembolism, long term anticoagulation for atrial fibrillation, and acute coronary 
syndromes. ${ }^{4}$ The role of the novel oral anticoagulants for treatment of acute venous thromboembolism has also been investigated in several randomised controlled trials, which were typically designed and powered to show non-inferiority to vitamin $\mathrm{K}$ antagonists in terms of recurrence of acute venous thromboembolism and risk of bleeding. These trials were limited in size and yielded inconclusive or conflicting results. Furthermore, the results have yet to be incorporated in a meta-analysis, which can reduce the amount of uncertainty surrounding the treatment effects. We conducted a systematic review and meta-analysis of randomised controlled trials for treatment of acute venous thromboembolism to obtain a better estimate of the benefits and risks of the different novel oral anticoagulants compared with vitamin $\mathrm{K}$ antagonists.

\section{Methods \\ Data sources and searches}

We searched Medline, Embase, and the Cochrane Library. Each database was searched from its inception date to 5 April 2012. Conference abstracts were included in our search. The retrieved articles were examined to eliminate potential duplicates or overlapping data. No limits or language restriction were applied during the search. The search string was: \#1. (rivaroxaban OR BAY 59-739) OR (apixaban or BMS-562247-01) OR (edoxaban OR DU-176b) OR (betrixaban OR PRT054021) OR (darexaban OR YM150) OR LY-517717 OR GW813893 OR TAK-442 OR PD0348292; \#2. (dabigatran OR BIBR1048) OR ximelagatran OR AZD0837; \#3. \#2 OR \#1; \#4. deep venous thrombosis OR deep vein thrombosis OR thrombophlebitis OR pulmonary embolis* OR DVT OR PE; \#5. \#3 AND \#4. We also hand searched the references of relevant articles for additional clinical trials not identified by the electronic search and contacted experts. Finally we searched clinicaltrials.gov for information on clinical trials that were terminated but unpublished.

\section{Study selection}

One reviewer (BDF) performed the database search and initial screening of titles and abstracts. Two investigators (BDF, AS) independently carried out full text screening of all eligible articles. We included a study if participants were patients with acute symptomatic venous thromboembolism (that is, deep vein thrombosis or pulmonary embolism, or both) objectively diagnosed with standard imaging techniques; the intervention was treatment with a novel oral anticoagulants with or without initial treatment with heparin; the comparison group was treatment with vitamin $\mathrm{K}$ antagonists always with initial treatment with heparin; the outcome was recurrent acute venous thromboembolism, bleeding, or all cause mortality; and it was a randomised controlled trial. Though the direct thrombin inhibitor ximelagatran was withdrawn from the market in 2006 because of concerns over hepatotoxicity, we elected to include these data for completeness.

\section{Data extraction and quality assessment}

Two reviewers (BDF and AS) independently extracted data on to a computer spreadsheet, with discrepancies resolved by consensus. Extracted data included first author, year of publication, study design, characteristics of patients, length of follow-up, drug and drug loading, and maintenance protocol. The efficacy endpoint was recurrent acute venous thromboembolism, as defined by the study protocol. Safety endpoints were major bleeding and all cause mortality. Major bleeding was defined uniformly across the studies (fatal bleeding, bleed into critical site, fall of $\geq 20 \mathrm{~g} / \mathrm{L}$ haemoglobin, or requirement for transfusion of two or more units of blood), whereas non-major bleeding was defined heterogeneously. If a study was designed as a dose finding study, we extracted data only for the dose that was used in subsequent clinical trials. Each study was graded for potential bias into low, high, and unclear according to the Cochrane Collaboration handbook. ${ }^{5}$

\section{Data synthesis and analysis}

Event data were pooled for recurrent acute venous thromboembolism, major bleeding, and all cause mortality. In the primary analysis we stratified the results by drug name. To examine a possible class effect we did a secondary analysis stratified by drug class. We used the DerSimonian and Laird random effects model, which accounts for variability both within studies and between studies, to estimate pooled risk ratios with their $95 \%$ confidence intervals for event data. ${ }^{6}$ Forest plots were created for each outcome. When there were no events in one treatment group, we used a 0.5 continuity correction. Statistical heterogeneity was assessed with the Cochrane $\mathrm{Q}$ statistic $(\mathrm{P}<0.1$ was considered significant). We also calculated the $\mathrm{I}^{2}$ statistic to estimate the proportion of variation attributable to heterogeneity between studies. For each analysis we assessed publication bias with a funnel plot.

In the absence of trials making head to head comparisons between novel oral anticoagulants, we performed an adjusted indirect comparison using a single common comparator-that is, vitamin $\mathrm{K}$ antagonists - using the Bucher technique. ${ }^{7}$ We excluded apixaban from the adjusted indirect comparison as it was examined in only one small clinical trial and excluded ximelagatran as it has been withdrawn from the market.

Therefore the adjusted indirect comparison was performed only between rivaroxaban and dabigatran. We used the $\mathrm{R}$ statistical software system v2.15.0 with the meta (v2.0.1) package for statistical analysis. ${ }^{89}$ Certain endpoints of potential interest were reported inconsistently between studies so pooling of data was not appropriate. We summarised these data in a qualitative review. The manuscript was drafted with reference to the preferred reporting items for systematic reviews and meta-analyses (PRISMA) checklist. ${ }^{10}$

\section{Results}

\section{Study characteristics}

Our search identified 1781 studies of interest, after removal of duplicates (fig $1 \Downarrow$ ). Most studies were eliminated during screening as the indication for anticoagulation was not acute venous thromboembolism. After we reviewed 20 full text articles, nine studies with over 16000 patients were suitable for data extraction and pooled analysis. The trials evaluated two factor Xa inhibitors (rivaroxaban (four randomised controlled trials, $n=8709$ ) and apixaban (one trial, $n=258$ )) and two direct thrombin inhibitors (dabigatran (two trials, $\mathrm{n}=5107$ ) and ximelagatran (two trials, $\mathrm{n}=2627)$ ) ${ }^{11-19}$ Four studies were phase II dose finding studies and five were phase III studies powered for non-inferiority against vitamin $\mathrm{K}$ antagonists. The length of follow-up ranged from two weeks to 12 months.

\section{Rivaroxaban}

Two small phase II studies (EINSTEIN-Dose and ODIXa) looked at rivaroxaban in patients with acute deep vein thrombosis and were primarily concerned with imaging endpoints, though the endpoints of interest for our study were also reported. ${ }^{11}{ }^{12}$ The main phase III studies were performed by the EINSTEIN investigators in a pair of open label 
non-inferiority studies. The EINSTEIN-DVT study enrolled 3449 patients with acute deep vein thrombosis and excluded patients with symptomatic pulmonary embolism. ${ }^{13}$ The EINSTEIN-PE study recruited 4832 patients with acute symptomatic pulmonary embolism with or without symptomatic deep vein thrombosis. ${ }^{14}$ After the phase II studies, the EINSTEIN investigators chose to load rivaroxaban at $15 \mathrm{mg}$ twice a day for two weeks followed $20 \mathrm{mg}$ four times a day for the remainder of the study. The rivaroxaban patients typically received one to two doses of low molecular weight heparin before starting rivaroxaban, whereas the patients randomised to vitamin $\mathrm{K}$ antagonists received low molecular weight heparin concurrently for five days or more, until the target international normalised ratio was achieved.

\section{Apixaban}

A single published phase II study (Botticelli study) looked at apixaban in patients with acute deep vein thrombosis. ${ }^{15}$ This formed the basis for an ongoing clinical trial of apixaban for the treatment of acute venous thromboembolism (clinicaltrials. gov NCT00643201). In a similar design to the rivaroxaban studies, the patients in the apixaban arm did not receive a full course of low molecular weight heparin.

\section{Dabigatran}

The pivotal published study on dabigatran was RECOVER I, which enrolled patients with deep vein thrombosis and pulmonary embolism. ${ }^{16}$ This was a phase III non-inferiority, double blind, double dummy trial, which included sham monitoring of international normalised ratio and sham titration of vitamin $\mathrm{K}$ antagonists in the experimental group. To obtain regulatory approval, the study was repeated (RECOVER II) with a similar design and the results published in abstract. ${ }^{17}$ Both patients who received dabigatran and those who received vitamin $\mathrm{K}$ antagonists received a full five day course of low molecular weight heparin before starting the study drug.

\section{Ximelagatran}

We found two published studies that looked at ximelagatran. THRIVE I was a short phase II study $(\mathrm{n}=138)$ on patients with acute deep vein thrombosis with an imaging endpoint. ${ }^{18}$ THRIVE I also reported event data. The phase III, THRIVE II and THRIVE V studies were reported together as one trial (referred to as THRIVE II/V in this study). ${ }^{19}$ The THRIVE II/V trial enrolled 2489 patients with acute deep vein thrombosis with or without pulmonary embolism in a double blind, double dummy randomised design similar to the RECOVER studies for dabigatran. Patients randomised to ximelagatran received dummy low molecular weight heparin with dummy vitamin $\mathrm{K}$ antagonists during the initial phase of the study.

\section{Risk of bias assessment}

Of the nine studies, we assessed the risk of bias as low in four studies and unclear in five studies (table $1 \Downarrow$ ). In the open label studies (with the exception of the THRIVE I study), outcome data were recorded with a routine structured technique and were adjudicated by an independent committee blinded to study drug allocation. In three of the five studies graded as having unclear potential for bias this was due to only a single domain, with all other domains classified as low potential for bias. One study (RECOVER II) has been published only in abstract form, so we could not completely assess potential biases or extract demographic data. ${ }^{17}$ As its design was similar to RECOVER I, however, we assumed that its potential bias would be either low or unclear at most. The funnel plots indicated low risk of publication bias for all analyses (see supplementary fig 1).

\section{Patients' characteristics}

There were 16701 patients in the efficacy analysis (recurrence of acute venous thromboembolism) and 16611 in the safety analysis (major bleeding and all cause mortality) (table $2 \Downarrow$ ). The mean age of patients ranged was 54-60 and 47-54\% were men. Trauma/surgery and previous acute venous thromboembolism were the most common associated risk factors described, though not all studies reported the same risk factors. In the comparison arms, the international normalised ratio was moderately well controlled, with $50-63 \%$ of measurements in the target range.

\section{Primary analysis: stratification by drug name}

For recurrent acute venous thromboembolism, we found no evidence of difference between any of the novel oral anticoagulants and the vitamin $\mathrm{K}$ antagonists for each comparison (fig $2 \Downarrow$ ). In the major bleeding meta-analysis (fig $3 \Downarrow$ ), the only drug associated with a decreased risk of major bleeding was rivaroxaban (relative risk $0.57,95 \%$ confidence interval 0.39 to 0.84 ), with no evidence of heterogeneity between studies $\left(\mathrm{I}^{2}=0 \%\right)$. For all cause mortality (fig $\left.4 \Downarrow\right)$, there was no evidence of differences in outcome between any of the novel oral anticoagulants and conventional treatment, with no evidence of heterogeneity between studies.

\section{Secondary analysis: stratification by pharmacological class}

For recurrent acute venous thromboembolism, there was no evidence of difference between any of the drugs and vitamin $\mathrm{K}$ antagonists, with evidence of no to mild heterogeneity $\left(\mathrm{I}^{2}=0-17 \%\right)$. In the major bleeding analysis, events occurred less often with both the direct thrombin inhibitors (relative risk 0.68 , $95 \%$ confidence interval 0.48 to 0.98 ) and the factor Xa inhibitors $(0.59,0.40$ to 0.85$)$. There was no evidence of heterogeneity in these comparisons $\left(\mathrm{I}^{2}=0 \%\right.$ for both). All cause mortality was similar to that seen with vitamin $\mathrm{K}$ antagonists for both classes of novel oral anticoagulants. There was evidence of no to mild heterogeneity this analysis $\left(\mathrm{I}^{2}=0-20 \%\right)$. All forest plots for the secondary analysis are provided in the supplementary files.

\section{Adjusted indirect comparison}

The adjusted indirect comparison was performed for active trial arms for rivaroxaban and dabigatran for each of the three endpoints. In this analysis, a relative risk $<1.0$ favours rivaroxaban and a relative risk $>1.0$ favours dabigatran. For each of the endpoints, there was no evidence of benefit of either drug over the other: relative risk 0.78 (0.49 to 1.24$)$ for acute venous thromboembolism; 0.75 (0.41 to 1.34$)$ for major bleeding; and 0.96 ( 0.59 to 1.58$)$ for all cause mortality.

\section{Qualitative summary}

\section{Rivaroxaban}

In the large EINSTEIN studies there were fewer study discontinuations among patients randomised to rivaroxaban (10.7-11.3\%) than among those randomised to vitamin $\mathrm{K}$ antagonists (12.3-14.2\%), driven by a high rate of withdrawal of consent in the vitamin $\mathrm{K}$ antagonists arm. There was no excess of increased liver enzyme activity, vascular events, or dyspepsia in patients taking rivaroxaban compared with vitamin $\mathrm{K}$ antagonists. The EINSTEIN study group introduced a novel 
endpoint "net clinical benefit," a composite of recurrent acute venous thromboembolism and major bleeding. ${ }^{13}{ }^{14}$ This parameter was not reported in other trials, and without patient level data we cannot calculate the net clinical benefit simply by adding acute venous thromboembolism and major bleeding events (H R Buller, personal communication). Of note, rivaroxaban reduced the risk for the net clinical benefit (pooled events from four randomised controlled trials: relative risk 0.79 , 0.63 to 0.99$)$

\section{Apixaban}

Apixaban was associated with slightly increased rates of non-major bleeding (11\% v 8\% vitamin $\mathrm{K}$ antagonists) and discontinuation (13\% v 8\% vitamin $\mathrm{K}$ antagonists). Apixaban was not associated with increased liver enzyme activity.

\section{Dabigatran}

Patients in the RECOVER I study had a higher rate of discontinuation because of dyspepsia in the dabigatran arm (2.9\% v $0.6 \%$ for vitamin $\mathrm{K}$ antagonists). Non-major bleeding was significantly decreased in the dabigatran arm of the RECOVER I study (hazard ratio $0.71,95 \%$ confidence interval 0.59 to 0.85 ). Dabigatran has been associated with increased risk of myocardial infarction, though this was not specifically noted in RECOVER I. ${ }^{20}$ Dabigatran was not associated with increased liver enzyme activity.

\section{Ximelagatran}

In the THRIVE II/V study, more patients were withdrawn in the ximelagatran arm of the study because of increased liver enzyme activity ( $10.2 \% v 2.2 \%$ for vitamin $\mathrm{K}$ antagonists). Ximelagatran was also associated with more vascular events than vitamin $\mathrm{K}$ antagonists $(0.8 \% v 0.08 \%)$, though these events were not adjudicated by an independent expert committee.

\section{Discussion}

This systematic review, meta-analysis, and adjusted indirect comparison of the novel oral anticoagulants compared with vitamin $\mathrm{K}$ antagonists for the treatment of acute venous thromboembolism showed no significant differences in the risk of recurrence and the risk of all cause mortality. There was a significant reduction in major bleeding with rivaroxaban. The magnitude of the reduction in major bleeding was less apparent for other novel oral anticoagulants and did not reach significance. Importantly, the sample sizes of the individual randomised controlled trials included in our meta-analysis were too small to provide reliable conclusions about the efficacy and safety of the novel oral anticoagulants. By pooling data across trials, we reduced the uncertainty surrounding the treatment effects and obtained more precise $95 \%$ confidence intervals.

\section{Novel findings}

As far as we know, this study is the first overall analysis of the novel oral anticoagulants for treatment of acute venous thromboembolism. The clinical trials in our systematic review were all funded by industry and powered for dose finding or for non-inferiority compared with conventional treatment. The non-inferiority design has certain advantages, such as potentially reducing the sample size, and the results can often be sufficient to obtain regulatory approval, but there are important nuances to their interpretation. ${ }^{21}$ The most important factor is the size of the "margin of inferiority," which in the aforementioned studies was the upper confidence limit for the target event's hazard ratio (2.0 in EINSTEIN-PE, 2.0 in EINSTEIN-DVT, and 2.75 in RECOVER I) or an absolute risk difference (4\% in THRIVE II/V)..$^{13} 141619$ In EINSTEIN-PE and RECOVER I, the study hazard ratios for recurrent acute venous thromboembolism were above 1.0 (that is, tending towards favouring vitamin $\mathrm{K}$ antagonists) and the upper confidence limit of the hazard ratio was close to but still within the margin of inferiority. By pooling results in this meta-analysis, the upper confidence limit of the relative risk for these agents moved closer to the point estimate, which suggests that these drugs are indeed non-inferior to the vitamin $\mathrm{K}$ antagonists in a total sample of over 16000 patients.

All of the novel oral anticoagulants (except in the small apixaban study) showed a trend towards lower rates of major bleeding compared with vitamin $\mathrm{K}$ antagonists, but this was significant only for rivaroxaban. This finding should be interpreted with caution for two reasons. Firstly, the rivaroxaban studies accounted for more than $53 \%$ of the participants in the whole meta-analysis so this finding might simply reflect the larger sample size. Secondly, in the indirect analysis comparing rivaroxaban with dabigatran there was no clear evidence of advantage for either drug, though the relative risk still trended towards rivaroxaban.

We also performed an adjusted indirect comparison analysis to evaluate potential risks/benefits of one novel oral anticoagulant over the other. The analysis of dabigatran and rivaroxaban did not show significant differences between the two drugs - the point estimate tended to favour rivaroxaban but the upper confidence limit crossed 1.0 in every case. Loke and Kwok published an adjusted indirect comparison of rivaroxaban and dabigatran based on studies on acute venous thromboembolism prophylaxis in orthopaedics, with low molecular weight heparin as the common comparator. ${ }^{22}$ Rivaroxaban was found to be superior to dabigatran, but there was a trend towards increased bleeding. Differences in therapeutic regimen and selection of patients could explain these discrepancies with our results. Clearly without properly executed clinical trials comparing the different novel oral anticoagulants it is not possible to know which might have the best efficacy and safety profile.

We also stratified pooling and meta-analysis of event data by pharmacological class (direct thrombin inhibitors or factor Xa inhibitor). The factor Xa inhibitors also decreased major bleeding, driven by the rivaroxaban studies, as discussed above. In addition, the direct thrombin inhibitors showed a reduction in risk of major bleeding compared with vitamin $\mathrm{K}$ antagonists treatment (five studies, $\mathrm{n}=7734$, see supplementary figure), whereas neither dabigatran or ximelagatran significantly reduced bleeding in our analysis by drug (fig $2 \Downarrow$ ). These findings should be interpreted cautiously because ximelagatran was withdrawn from the market in 2006.

\section{Comparisons with other studies}

The novel oral anticoagulants have been tested in clinical trials for other indications, including thromboprophylaxis in atrial fibrillation, medical and surgical inpatients, and acute coronary syndromes. ${ }^{4}$ These studies often used different doses to those used in the acute venous thromboembolism studies. In addition, the comparator arm might have been placebo, parenteral anticoagulants, or vitamin $\mathrm{K}$ antagonists, depending on the study. For example, patients with acute coronary syndromes were at a higher risk of bleeding (2.2\% for rivaroxaban in the ATLAS ACS 2-TIMI 51 trial) as they were typically treated with antiplatelet agents. ${ }^{23}$ In contrast, in atrial fibrillation studies, the novel oral anticoagulants were associated with similar risk of major bleeding (relative risk $0.88,95 \%$ confidence interval 
0.71 to 1.09$).{ }^{24}$ In our study the rate of major bleeding in the included studies ranged from $0.4 \%$ to $1.73 \%$. Similarly, after lower limb orthopaedic surgery patients have a lower risk of first acute venous thromboembolism $(0.5-1.0 \%)$ than the higher risk of recurrent acute venous thromboembolism seen in the trials analysed in our study (1.4-4.6\%). ${ }^{25}$ Thus, we believe that comparison of our results with these prophylaxis studies would be invalid. In line with the results from these studies, however, it seems that novel oral anticoagulants might be an effective and safe alternative to conventional treatment for acute venous thromboembolism.

\section{Limitations}

Our study has several potential limitations. Firstly, we pooled studies with both deep vein thrombosis and pulmonary embolism under the umbrella diagnosis of acute venous thromboembolism. While trial designers might have had specific reasons for separating the two presentations for regulatory or potential safety reasons, it is accepted in clinical practice that they are fundamentally the same. For example, in the THRIVE II/V study, clinically silent but radiologically proved pulmonary embolism was seen in $37 \%$ of patients, which is consistent with previous literature. ${ }^{19} \mathrm{We}$ therefore contend that pooling of deep vein thrombosis/pulmonary embolism studies together is medically correct and allows pooling of a larger number of patients to obtain more precise treatment effects. Secondly, most randomised controlled trials had an open label design because of the complexity and futility of monitoring international normalised ratio in the novel oral anticoagulant arm. All outcomes, however, were assessed by blinded observers and all efficacy and safety outcomes were adjudicated by a committee in each trial, and acute venous thromboembolism outcomes required confirmation with imaging. ${ }^{26}$ Thirdly, clinical trials are underway for apixaban (clinicaltrials.gov NCT00643201) and edoxaban (clinicaltrials.gov NCT009861154), and further meta-analysis will be required on this subject in due course. In the interim, we believe that this systematic review of all available randomised controlled trials offers the most comprehensive appraisal of the literature to date. Fourthly, durations of follow-up and treatment varied between randomised controlled trials, which could limit the interpretation of the meta-analysis for a specific length of treatment. Our analyses, however, have shown little or no heterogeneity between randomised controlled trials for all outcomes. Fifthly, in common with many clinical trials, study participants might have been younger, healthier, and more closely monitored than the general population with acute venous thromboembolism. This could limit the generalisablility of our findings. Finally, secondary outcomes such as minor bleeding and adverse events were not pooled, and we could not perform subgroup analysis according to the aetiology of acute venous thromboembolism because of the lack of patient level data. These analyses might be important to guide the clinical management in different groups of patients with acute venous thromboembolism.

\section{Conclusions}

In conclusion, the novel oral anticoagulants had similar efficacy and mortality profiles compared with conventional anticoagulation with vitamin $\mathrm{K}$ antagonists. Rivaroxaban was associated with lower risk of major bleeding. Given the lack of evidence from our adjusted indirect comparison to suggest the superiority of any one novel oral anticoagulant over another, there remains a need for large randomised controlled trials powered to directly compare these novel agents.
BDF is supported in part by the William Pencer Family Foundation. AS is supported by the Azrieli Foundation and a Susan Raymer cardiology fellowship grant. SRK and MJE are supported by a national investigator award of the Fonds de la recherche en santé du Québec (FRSQ). DL receives support from the Bank of Montreal Center for the Study of Heart Disease in Women, and the Dimitrious Banousis Foundation. Contributors: BDF conceived the study, performed the systematic review, data extraction, and data analysis, and drafted the manuscript. SRK, MJE, and DL conceived the study, analysed the data, and reviewed the manuscript for important intellectual content. AS conceived the study, performed the systematic review, data extraction, and analysis, and reviewed the manuscript for important intellectual content. All authors had full access to the data and take responsibility for the integrity of the data and accuracy of the analysis. BDF is guarantor.

Funding: This research received no specific grant from any funding agency in the public, commercial, or not-for-profit sectors.

Competing interests: All authors have completed the ICMJE uniform disclosure form at www.icmje.org/coi_disclosure.pdf (available on request from the corresponding author) and declare: no support from any organisation for the submitted work; no financial relationships with any organisations that might have an interest in the submitted work in the previous three years; no other relationships or activities that could appear to have influenced the submitted work.

Ethical approval: Not required.

Data sharing:No additional data available.

1 Kearon C, Akl EA, Comerota AJ, Prandoni P, Bounameaux H, Goldhaber SZ, et al. Antithrombotic therapy for VTE disease: antithrombotic therapy and prevention of thrombosis, 9th ed: American College of Chest Physicians Evidence-Based Clinical Practice Guidelines. Chest 2012;141:e419-94S.

2 Ageno W, Gallus AS, Wittkowsky A, Crowther M, Hylek EM, Palareti G, et al. Oral anticoagulant therapy: antithrombotic therapy and prevention of thrombosis, 9th ed: American College of Chest Physicians Evidence-Based Clinical Practice Guidelines. Chest 2012;141:e44-88S.

3 Weitz JI. New oral anticoagulants: a view from the laboratory. Am J Hematol 2012;:S1:S133-6.

4 Weitz JI, Eikelboom JW, Samama MM, American College of Chest Physicians. New antithrombotic drugs: antithrombotic therapy and prevention of thrombosis, 9th ed: American College of Chest Physicians Evidence-Based Clinical Practice Guidelines. Chest 2012;141:e120-51S.

5 Higgins JPT, Green S. Cochrane handbook for systematic reviews of interventions 5.1.0. Cochrane Collaboration, 2011

6 DerSimonian R, Laird N. Meta-analysis in clinical trials. Control Clin Trials 1986;7:177-88.

7 Glenny AM, Altman DG, Song F, Sakarovitch C, Deeks JJ, D'amico D, et al. Indirect comparisons of competing interventions. Health Technol Assess 2005;9:1-134.

8 R Development Core Team. R: a language and environment for statistical computing. R Foundation for Statistical Computing, 2012.

9 Schwarzer G. meta: Meta-analysis with R, 2012. R package version 2.0-1. 2012. http:// cran.r-project.org/web/packages/meta/.

10 Moher D, Liberati A, Tetzlaff J, Altman DG. Preferred reporting items for systematic reviews and meta-analyses: the PRISMA statement. PLOS Med 2009:6:e10000097.

11 Buller HR, Lensing AWA, Prins MH, Agnelli G, Cohen A, Gallus AS, et al. A dose-ranging study evaluating once-daily oral administration of the factor $X$ inhibitor rivaroxaban in the treatment of patients with acute symptomatic deep vein thrombosis: the Einstein-DVT Dose-Ranging Study. Blood 2008;112:2242-7.

12 Agnelli G, Gallus A, Goldhaber SZ, Hass S, Huisman MV, Hull RD, et al. Treatment of proximal deep-vein thrombosis with the oral direct factor Xa inhibitor rivaroxaban (bay 59-7939): the ODIXa-DVT (Oral Direct Factor Xa inhibitor BAY 59-7939 in patients with acute symptomatic deep-vein thrombosis) study. Circulation 2007;116:180-7.

13 EINSTEIN investigators. Oral rivaroxaban for symptomatic venous thromboembolism. N Engl J Med 2010;363:2499-510.

14 EINSTEIN-PE investigators. Oral rivaroxaban for the treatment of symptomatic pulmonary embolism. N Engl J Med 2012;366:1287-97.

15 Buller H, Deitchman D, Prins M, Segers A. Efficacy and safety of the oral direct factor Xa inhibitor apixaban for symptomatic deep vein thrombosis. The Botticelli DVT dose-ranging study. J Thromb Haemost 2008;6:1313-8.

16 Schulman S, Kearon C, Kakkar AK, Mismetti P, Schellong, S, Eriksson H, et al. Dabigatran versus warfarin in the treatment of acute venous thromboembolism. $N$ Engl J Med 2009;361:2342-52.

17 Schulman S, Kakkar AK, Schellong SM, Goldhaber SZ, Henry E, Mismetti P, et al. A Randomized trial of dabigatran versus warfarin in the treatment of acute venous thromboembolism (RE-COVER II) ASH Annual Meeting Abstracts. Blood 2011;118:205.

18 Eriksson $\mathrm{H}$, Wåhlander K, Gustafsson D, Welin LT, Frison L, Schulman S, et al. A randomized, controlled, dose-guiding study of the oral direct thrombin inhibitor ximelagatran compared with standard therapy for the treatment of acute deep vein thrombosis: THRIVE 1. J Thromb Haemost 2003:1:41-7.

19 Fiessinger JN, Huisman MV, Davidson BL, Bounameaux H, Francis CW, Eriksson H, et al. Ximelagatran vs low-molecular-weight heparin and warfarin for the treatment of deep vein thrombosis: a randomized trial. JAMA 2005;293:681-9.

20 Uchino K, Hernandez AV. Dabigatran association with higher risk of acute coronary events: meta-analysis of noninferiority randomized controlled trials. Arch Intern Med 2012;172:397-402. 


\section{What is already known on this topic}

Traditional treatment of acute venous thromboembolism with vitamin $\mathrm{K}$ antagonists is effective but is complex to manage and is associated with an increased risk of bleeding

Novel anticoagulants that do not require laboratory monitoring are available and have been evaluated in clinical trials, although without clear cut results as to the superiority of one treatment over the other

\section{What this study adds}

A meta-analysis of all available data showed that the novel oral anticoagulants are associated with a similar risk of recurrence of acute venous thromboembolism compared with standard treatment with vitamin $\mathrm{K}$ antagonists

The novel oral anticoagulant rivaroxaban (a factor Xa inhibitor) was associated with a reduced risk of bleeding

21 Gøtzsche PC. Lessons from and cautions about noninferiority and equivalence randomized trials. JAMA 2006;295:1172-4.

22 Loke YK, Kwok CS. Dabigatran and rivaroxaban for prevention of venous thromboembolism-systematic review and adjusted indirect comparison. J Clin Pharm The 2011;36:111-24.

23 Mega JL, Braunwald E, Wiviott SD, Trippoli S, Messori A. Rivaroxaban in patients with a recent acute coronary syndrome. N Engl J Med 2012;366:9-19.

24 Miller CS, Grandi SM, Shimony A, Filion KB, Eisenberg MJ. Meta-analysis of efficacy and safety of new oral anticoagulants (dabigatran, rivaroxaban, apixaban) versus warfarin in patients with atrial fibrillation. Am J Cardiol 2012;110:453-60.

25 Januel JM, Chen G, Ruffieux C, Quan H, Douketis JD, Crowther MA, et al. Symptomatic in-hospital deep vein thrombosis and pulmonary embolism following hip and knee arthroplasty among patients receiving recommended prophylaxis: a systematic review. JAMA 2012;307:294-303.
26 Buller HR, Halperin JL, Bounameaux H, Prins M. Double-blind studies are not always optimum for evaluation of a novel therapy: the case of new anticoagulants. $J$ Thromb Haemost 2008;6:227-9.

\section{Accepted: 01 October 2012}

\section{Cite this as: BMJ 2012;345:e7498}

This is an open-access article distributed under the terms of the Creative Commons Attribution Non-commercial License, which permits use, distribution, and reproduction in any medium, provided the original work is properly cited, the use is non commercial and is otherwise in compliance with the license. See: http://creativecommons.org/licenses/by$\mathrm{nc} / 2.0 /$ and http://creativecommons.org/licenses/by-nc/2.0/legalcode. 


\section{Tables}

\begin{tabular}{|c|c|c|c|c|c|c|c|}
\hline Study & Patients & Novel oral anticoagulant & Design & Efficacy & Safety & Duration & Risk of bias \\
\hline \multicolumn{8}{|c|}{ Factor Xa inhibitor-rivaroxaban } \\
\hline $\begin{array}{l}\text { EINSTEIN-PE, } \\
2012^{14}\end{array}$ & $\begin{array}{l}\text { Symptomatic pulmonary } \\
\text { embolism, } n=4832\end{array}$ & $\begin{array}{l}\text { Rivaroxaban: } 15 \mathrm{mg} \text { twice a day } \\
\text { for } 3 \text { weeks, } 20 \mathrm{mg} \text { four times a } \\
\text { day thereafter }\end{array}$ & $\begin{array}{l}\text { Open label, randomised, } \\
\text { non-inferiority }\end{array}$ & ITT & PP & $\begin{array}{l}3,6, \text { or } 12 \\
\text { months }\end{array}$ & Low \\
\hline $\begin{array}{l}\text { EINSTEIN-DVT, } \\
2010^{13}\end{array}$ & $\begin{array}{l}\text { Proximal deep vein } \\
\text { thrombosis, } n=3449\end{array}$ & $\begin{array}{l}\text { Rivaroxaban: } 15 \mathrm{mg} \text { twice a day } \\
\text { for } 3 \text { weeks, } 20 \mathrm{mg} \text { four times a } \\
\text { day thereafter }\end{array}$ & $\begin{array}{l}\text { Open label, randomised, } \\
\text { non-inferiority }\end{array}$ & ITT & PP & $\begin{array}{l}3,6, \text { or } 12 \\
\text { months }\end{array}$ & Low \\
\hline $\begin{array}{l}\text { EINSTEIN-Dose, } \\
2008^{11}\end{array}$ & $\begin{array}{l}\text { Proximal or extensive distal } \\
\text { deep vein thrombosis, } n=216\end{array}$ & $\begin{array}{l}\text { Rivaroxaban: } 20-40 \mathrm{mg} \text { four times } \\
\text { a day, } 20 \mathrm{mg} \text { four times a day } \\
\text { extracted }\end{array}$ & $\begin{array}{l}\text { Open label, randomised, } \\
\text { phase II }\end{array}$ & PP & PP & 12 weeks & Unclear \\
\hline ODIXa, $2007^{12}$ & $\begin{array}{l}\text { Proximal deep vein } \\
\text { thrombosis, } n=212\end{array}$ & $\begin{array}{l}\text { Rivaroxaban: } 10-40 \mathrm{mg} \text { four times } \\
\text { a day, } 20 \mathrm{mg} \text { four times a day } \\
\text { extracted }\end{array}$ & $\begin{array}{l}\text { Open label, randomised, } \\
\text { phase II }\end{array}$ & ITT & PP & 12 weeks & Unclear \\
\hline \multicolumn{8}{|c|}{ Factor Xa inhibitor-apixaban } \\
\hline Botticelli, $2008^{15}$ & $\begin{array}{l}\text { Proximal or extensive distal } \\
\text { deep vein thrombosis, } n=258\end{array}$ & $\begin{array}{l}\text { Apixaban: } 5-20 \mathrm{mg} \text { four times a } \\
\text { day, } 5 \mathrm{mg} \text { four times a day } \\
\text { extracted }\end{array}$ & $\begin{array}{l}\text { Open label, randomised, } \\
\text { phase II }\end{array}$ & ITT & PP & $12-13$ weeks & Unclear \\
\hline \multicolumn{8}{|c|}{ Direct thrombin inhibitor-dabigatran } \\
\hline $\begin{array}{l}\text { RECOVER II, } \\
2011^{17}\end{array}$ & $\begin{array}{l}\text { All acute venous } \\
\text { thromboembolism, } n=2568\end{array}$ & Dabigatran: $150 \mathrm{mg}$ twice a day & $\begin{array}{l}\text { Double blind, randomised, } \\
\text { non-inferiority }\end{array}$ & - & - & 6 months & Unclear \\
\hline $\begin{array}{l}\text { RECOVER I, } \\
2009^{16}\end{array}$ & $\begin{array}{l}\text { All acute venous } \\
\text { thromboembolism, } n=2539\end{array}$ & Dabigatran: $150 \mathrm{mg}$ twice a day & $\begin{array}{l}\text { Double blind, randomised, } \\
\text { non-inferiority }\end{array}$ & ITT & PP & 6 months & Low \\
\hline \multicolumn{8}{|c|}{ Direct thrombin inhibitor-ximelagatran } \\
\hline THRIVE II/V, $2005^{19}$ & $\begin{array}{l}\text { Proximal deep vein } \\
\text { thrombosis, } n=2489\end{array}$ & Ximelagatran: 36 mg twice a day & $\begin{array}{l}\text { Double blind, randomised, } \\
\text { non-inferiority }\end{array}$ & ITT & PP & 6 months & Low \\
\hline THRIVE I, $2003^{18}$ & $\begin{array}{l}\text { Proximal deep vein } \\
\text { thrombosis, } n=138\end{array}$ & $\begin{array}{l}\text { Ximelagatran: } 24-60 \mathrm{mg} \text { twice a } \\
\text { day, } 36 \mathrm{mg} \text { extracted }\end{array}$ & $\begin{array}{l}\text { Open label, randomised, } \\
\text { phase II }\end{array}$ & ITT & PP & 2 weeks & Unclear \\
\hline
\end{tabular}


Table 2| Participants in studies of novel oral anticoagulants (NOA) for treatment of acute venous thromboembolism (VTE). Figures are percentages of patients unless stated otherwise, absolute numbers of patients in each group are given in table 3

\begin{tabular}{|c|c|c|c|c|c|c|}
\hline & Mean age (years) & Men (\%) & INR control (\%) & Previous VTE (\%) & Malignancy (\%) & Trauma/surgery (\%) \\
\hline Study & NOA Control & NOA Control & $<2.0 \quad 2.0-3.0>3.0$ & Control & NOA Control & Control \\
\hline
\end{tabular}

Factor Xa inhibitor-rivaroxaban

\begin{tabular}{lccccccccccccc}
\hline EINSTEIN-PE $^{14}$ & 57.9 & 57.5 & 54 & 5 & 22 & 63 & 16 & 19 & 20 & 5 & 5 & 17 \\
\hline EINSTEIN-DVT $^{13}$ & 55.8 & 56.4 & 57 & 56 & 24 & 58 & 16 & 19 & 19 & 6 & 5 & 19 & 19 \\
\hline EINSTEIN-Dose $^{11}$ & 58 & 57 & 47 & 51 & 29 & 50 & 20 & 21 & 29 & 8 & 7 & 19 \\
\hline ODIXa $^{12}$ & 57.5 & 58.4 & 57 & 61 & - & 60 & - & - & - & - & - & - & - \\
\hline
\end{tabular}

Factor Xa inhibitor-apixaban

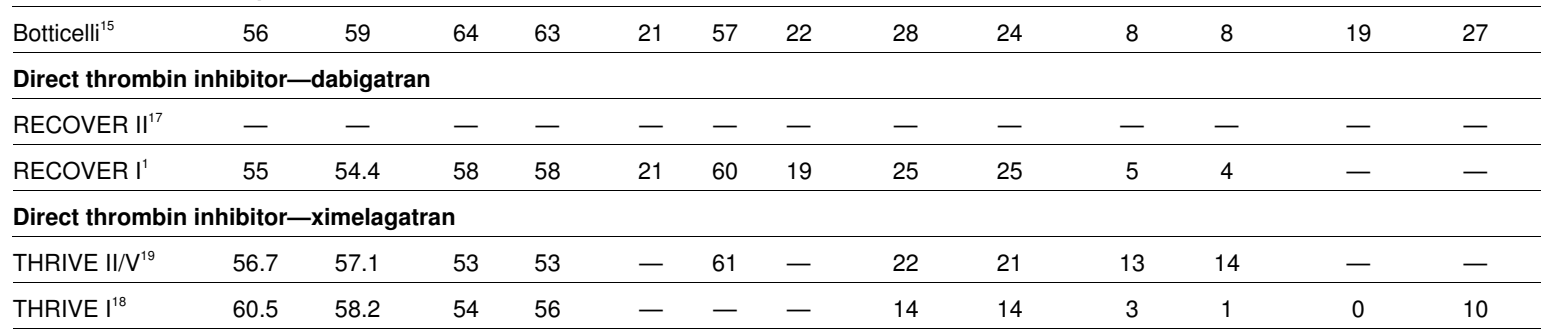

INR=international normalised ratio. 


\section{Figures}

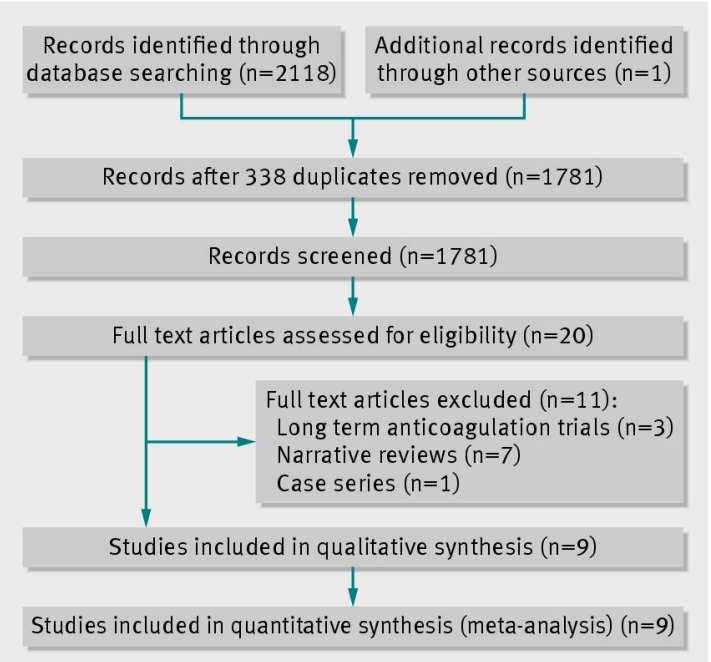

Fig 1 Flow diagram of search strategy for studies of novel oral anticoagulants for treatment of acute venous thromboembolism

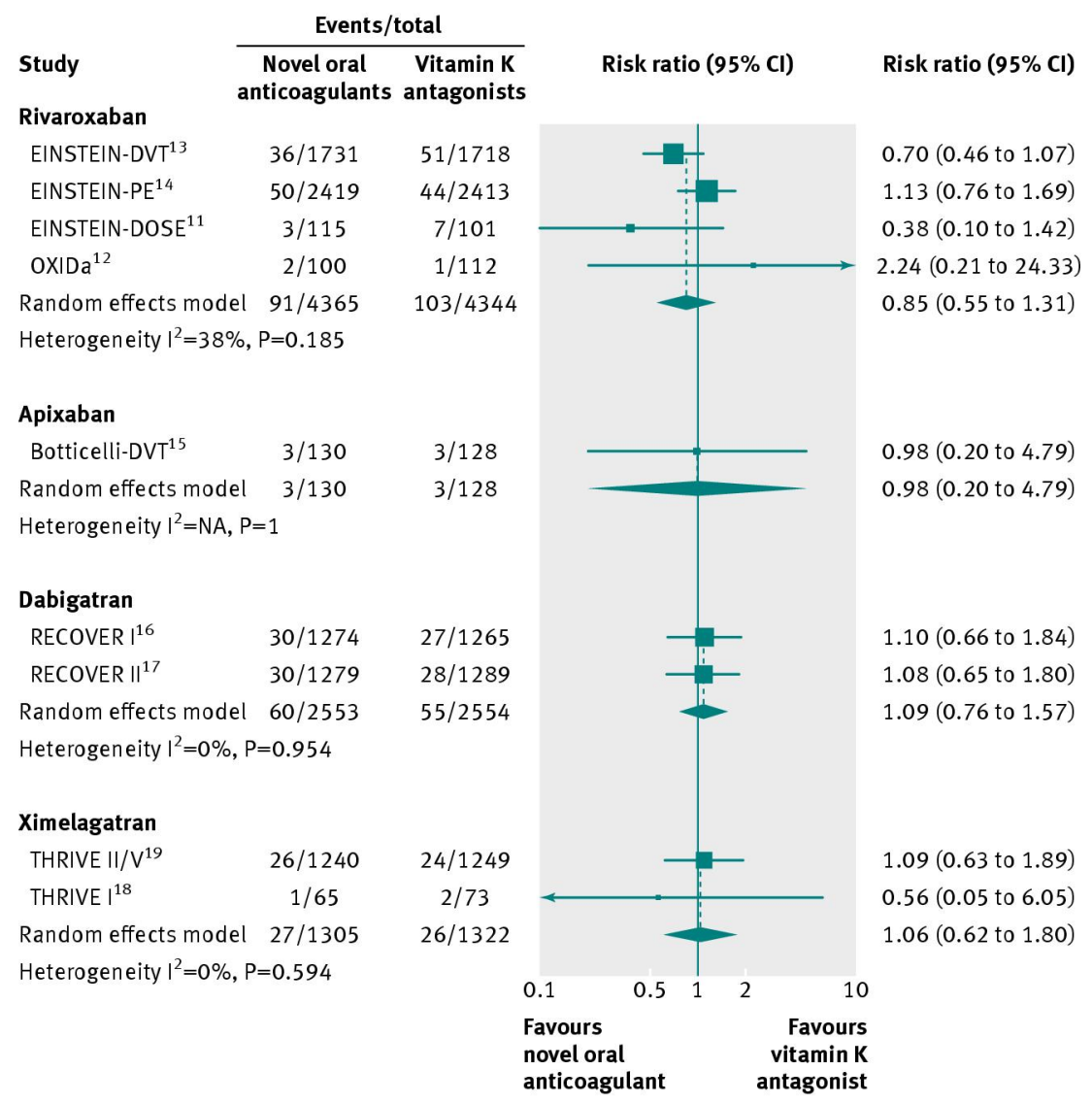

Fig 2 Relative risk for recurrent venothromboembolism with novel anticoagulants $v$ traditional treatment with vitamin $\mathrm{K}$ antagonists 


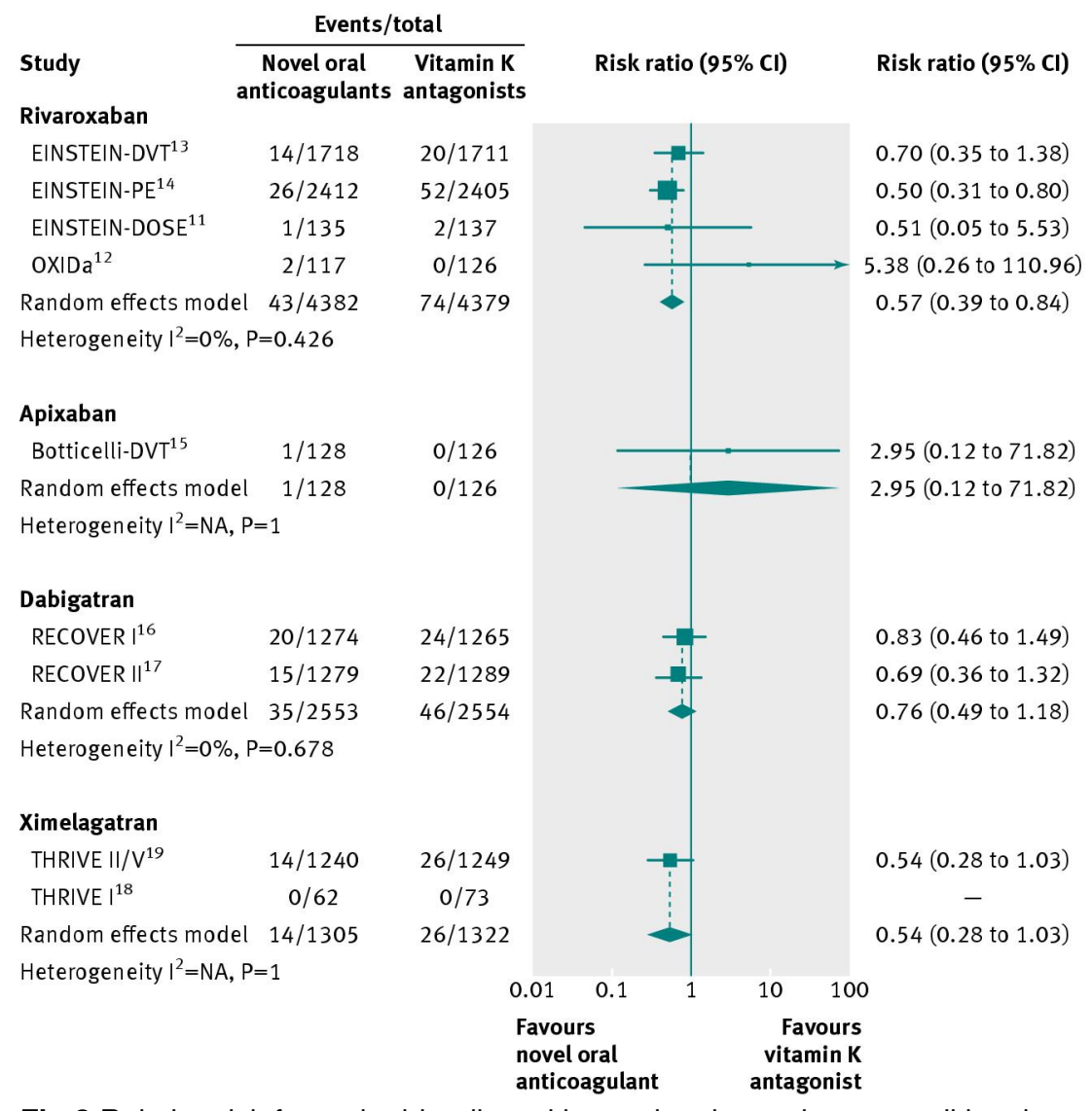

Fig 3 Relative risk for major bleeding with novel anticoagulants $v$ traditional treatment with vitamin $\mathrm{K}$ antagonists

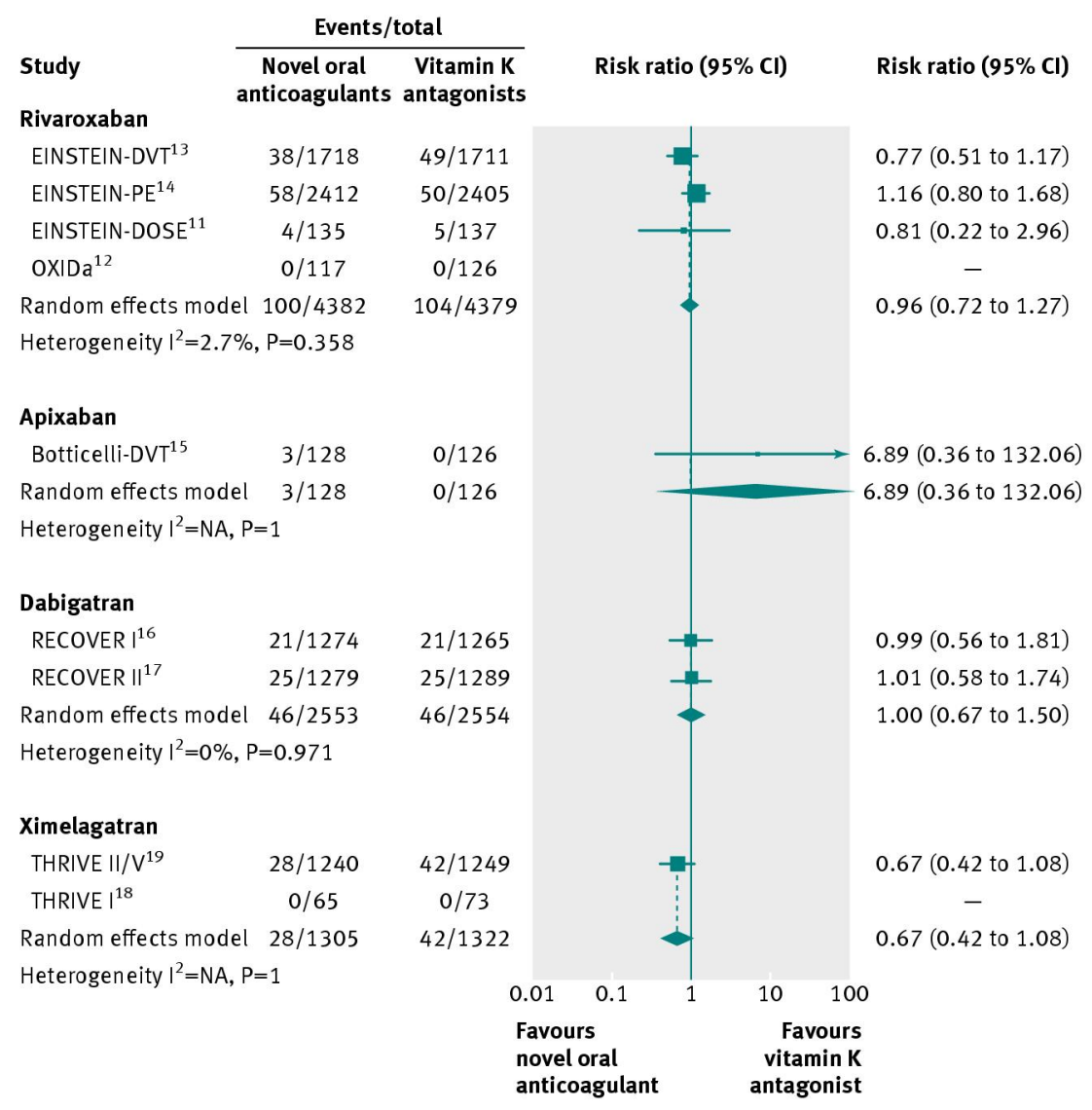

Fig 4 Relative risk for all cause mortality with novel anticoagulants $v$ traditional treatment with vitamin $\mathrm{K}$ antagonists 